\title{
Invasive Haemophilus influenzae type b infections in vaccinated and unvaccinated children in Canada, 2001-2003
}

\author{
David Scheifele, Scott Halperin, Barbara Law, Arlene King, for the Canadian Paediatric Society / \\ Health Canada Immunization Monitoring Program, Active (IMPACT)
}

Abstract

Background: Although vaccination of infants against Haemophilus influenzae type $\mathrm{b}$ (Hib) invasive infections is effective and has been routinely available in Canada since 1992, cases of the disease continue to occur. We were interested in determining whether recent cases of Hib infection reflected progressive loss of protection with time since vaccination, increasing nonacceptance of vaccination or a deleterious effect of coadministration of recently introduced vaccines such as those for pneumococcal and meningococcal conjugates and hepatitis B. We report on the causes of Hib infections among vaccinated and unvaccinated children between 2001 and 2003 in Canada.

Methods: Through our established network of 12 pediatric tertiary care hospitals we actively searched for cases in each centre by reviewing daily admissions and laboratory reports, visiting the wards and checking discharge diagnosis codes. Cultureconfirmed cases were summarized by nurse monitors using a standardized reporting system.

Results: We identified 29 cases during the 3 years: 16 in 2001, 10 in 2002 and 3 in 2003. Half of the 29 patients had meningitis. Hib infection was more common among children less than 6 months of age (11 cases) and in boys (20 cases). Two deaths occurred ( $7 \%$ case-fatality ratio). A total of 20 children had received no or incomplete primary vaccination because of parental refusal (7 cases), because they were too young to have completed the primary series (11 cases, including 1 in which parental refusal was also a factor) or because of delays in completing the primary series (2 cases); the vaccination history was uncertain in the remaining case. Infection despite primary vaccination occurred in 9 children: 2 previously healthy children and 7 who were immunocompromised or who had a predisposing condition. None of the cases identified in 2003 involved children who had received any of the newly introduced vaccines.

Interpretation: Invasive Hib infections remain rare in Canada, with most cases occurring in children too young to have completed the primary series. Protection after vaccination appears to extend into later childhood and does not appear to be diminished by coadministration of newer infant vaccines.
$\mathrm{U}$ ntil recently Haemophilus influenzae type b (Hib) was a leading cause of meningitis, epiglottitis and other invasive infections in children, affecting about 1 child in 250 by 5 years of age. ${ }^{1}$ The risk of infection was highest among children 6-24 months of age. Antibodies directed against the Hib capsular polysaccharide (polyribosyl ribitol phosphate, PRP) form the basis of protection. PRP protein conjugate vaccines that elicit anti-PRP responses in young infants have been used in Canada since 1992. Doses are recommended at 2, 4 and 6 months of age to establish protection and at 18 months to reinforce it. Since 1995 all provinces have used the same Hib vaccine (a PRP-tetanus protein conjugate [PRP-T], produced by Aventis Pasteur), in combination products based on wholecell pertussis vaccines (from 1995 to 1997) or acellular pertussis vaccines (1998 to the present).

Invasive Hib infections have been monitored since 1992 by a network of Canadian pediatric hospitals known as the Immunization Monitoring Program, Active (IMPACT). ${ }^{2}$ In 1985, before the first Hib vaccine was licensed, 485 invasive Hib cases were seen at 10 centres (those participating in IMPACT when the "look-back" was done). ${ }^{3}$ Case totals fell progressively as better vaccines became available. ${ }^{3-5}$ In 2000, only 4 cases were recorded by the IMPACT centres (which by then numbered 12), 99\% fewer than in $1985 .{ }^{\circ}$ Continuing surveillance is important to assess the effectiveness of the current schedule and vaccine. Because Hib vaccination is relatively new, the question of duration of protection remains open. Resurgence of Hib disease occurred recently in the United Kingdom, ${ }^{7}$ prompting addition of a booster dose to the vaccination schedule (as in Canada). Other questions of relevance are whether nonacceptance of Hib vaccine is influencing case totals and whether coadministration of newer vaccines, such as those for pneumococcal and meningococcal group $\mathrm{C}$ conjugates and hepatitis $\mathrm{B}$, is adversely affecting Hib responses. A reduced response is most likely to occur when infants are given conjugate vaccines containing the same carrier protein, ${ }^{8}$ which is not the case with PRP-T and pneumococcal 
conjugate vaccines; however, their compatibility has not been formally demonstrated to date. In this report we present details of cases encountered by IMPACT in the pe$\operatorname{riod} 2001$ to 2003.

\section{Methods}

The surveillance method has been described in detail elsewhere. $^{3-5}$ In brief, IMPACT comprises 12 pediatric centres from coast to coast, representing about $90 \%$ of the nation's tertiary care pediatric beds. About $45 \%$ of Canadian children live near an IMPACT centre. A nurse monitor at each centre searched for cases by reviewing daily admissions, liaising with microbiology staff and visiting the wards. Monitors confirmed the completeness

\section{Table 1: Haemophilus influenzae type b cases at IMPACT centres, 2001 to 2003}

\begin{tabular}{|c|c|c|c|c|}
\hline \multirow[b]{2}{*}{ Characteristic } & \multicolumn{4}{|c|}{ Year; no. of cases* } \\
\hline & $\begin{array}{c}2001 \\
n=16\end{array}$ & $\begin{array}{c}2002 \\
n=10\end{array}$ & $\begin{array}{l}2003 \\
n=3\end{array}$ & $\begin{array}{c}\text { Total } \\
n=29\end{array}$ \\
\hline \multicolumn{5}{|l|}{ Age } \\
\hline$\leq 5 \mathrm{mo}$ & 7 & 4 & 0 & 11 \\
\hline $6-12 \mathrm{mo}$ & 3 & 1 & 0 & 4 \\
\hline $1-2 \mathrm{yr}$ & 4 & 2 & 0 & 6 \\
\hline $3-5 y r$ & 1 & 1 & 1 & 3 \\
\hline$\geq 6 \mathrm{yr}$ & 1 & 2 & 2 & 5 \\
\hline Sex ratio (male:female) & $12: 4$ & $5: 5$ & $3: 0$ & $20: 9$ \\
\hline Attributable deaths & 1 & 1 & 0 & 2 \\
\hline Case-fatality ratio, $\%$ & 6 & 10 & - & 7 \\
\hline \multicolumn{5}{|l|}{ Place of residence } \\
\hline IMPACT city & 4 & 5 & 2 & 11 \\
\hline Other (referred) & 12 & 5 & 1 & 18 \\
\hline \multicolumn{5}{|l|}{ Major presenting syndrome } \\
\hline Meningitis & 9 & 5 & 1 & 15 \\
\hline Pneumonia with bacteremia & 2 & 2 & 2 & 6 \\
\hline Epiglottitis & 2 & 2 & 0 & 4 \\
\hline Septic arthritis & 1 & 0 & 0 & 1 \\
\hline Cellulitis & 1 & 0 & 0 & 1 \\
\hline Isolated bacteremia & 1 & 1 & 0 & 2 \\
\hline \multicolumn{5}{|l|}{ Immunization failure } \\
\hline Previously healthy child & 0 & 2 & 0 & 2 \\
\hline Immunocompromised child & 2 & 1 & 1 & 4 \\
\hline $\begin{array}{l}\text { Chronic condition, normal } \\
\text { immunity }\end{array}$ & 1 & 0 & 2 & 3 \\
\hline Total & 3 & 3 & 3 & 9 \\
\hline \multicolumn{5}{|l|}{ No or incomplete immunization } \\
\hline Parental refusal & 4 & $3 \dagger$ & 0 & 7 \\
\hline $\begin{array}{l}\text { Too young to have completed } \\
\text { primary series }\end{array}$ & 7 & $4 \dagger$ & 0 & 11 \\
\hline $\begin{array}{l}\text { Delayed completion of primary } \\
\text { series }\end{array}$ & 2 & 0 & 0 & 2 \\
\hline Uncertain vaccination history & 0 & 1 & 0 & 1 \\
\hline Total & 13 & 7 & 0 & 20 \\
\hline
\end{tabular}

Note: IMPACT = Immunization Monitoring Program, Active.

*Unless specified otherwise.

tOne child appears in both categories, but the column total has been corrected for the duplication. of case-finding by auditing relevant discharge diagnosis codes with health records staff and checking Hib isolate lists in the laboratory. Eligible cases had Hib isolated from a normally sterile body site or fluid (e.g., blood, spinal fluid). Isolates were serotyped by the IMPACT centre laboratory or provincial reference laboratory. Cases were summarized by chart review using a specific report form. Monitors obtained details of prior Hib vaccinations (including reasons for non-vaccination when known) from the chart, doctor or health department. Reports were collated at the project data centre. We used the $t$ distribution to calculate $95 \%$ confidence intervals for the mean number of annual cases. The project was approved by the research ethics boards of participating centres.

\section{Results}

Over the 3-year period we detected 29 cases (Table 1). A large subset of the subjects (11 children) were less than 6 months of age, too young to have completed the recommended primary series of vaccinations, although parental refusal was a contributing factor in 1 case (Table 1). Cases were progressively less frequent over the 3 years, with only 3 infections being reported in 2003. The most common diagnosis was meningitis, present in half of the cases.

Predisposing factors were present in 8 children, including dysgammaglobulinemia, hypogammaglobulinemia, nephrotic syndrome treated with corticosteroids, prematurity (29 weeks' gestational age), ventriculoperitoneal shunt, transnasal hypophysectomy, HIV infection and severe chronic comorbidity. All had received 1 or more doses of Hib vaccine.

The vaccination history was obtained for every child. Nine cases involved immunization failure, defined as onset of infection 4 or more weeks after completion of primary vaccination. ${ }^{3}$ Only 2 failures involved previously healthy children. Five children had received 4 age-appropriate doses of Hib vaccine (as DTaP.IPV.Hib combination vaccine [diphtheria and tetanus toxoids, acellular pertussis, inactivated poliomyelitis and Hib tetanus protein conjugate vaccine]); of these, 4 had predisposing conditions and 1 was previously healthy. Three children had received 3 primary doses of Hib vaccine (as DTaP.IPV.Hib vaccine); 2 had predisposing conditions and 1 was previously healthy. One failure occurred 10 years after a single age-appropriate dose of an earlier Hib vaccine (not PRP-T), in a child with HIV infection.

Twenty children had received no or incomplete primary vaccination. Parental refusal of vaccination was associated with invasive Hib infection in 7 children, 6 of whom were old enough to have completed the primary series. Four of these children had meningitis and 2 had epiglottitis. Eleven children were too young to have completed a primary series: 3 were too young for the first dose, 6 had received only the first dose at 2 months, 1 had received 2 doses, and 1 was unvaccinated at 5 months of age. Two children who were older than 6 months had not completed a primary series. The vaccination history was incomplete for one 11-month-old child. 
Seven of the children identified during the 3-year period resided in the Yukon Territory, Nunavut or the Northwest Territories. Each had meningitis, which was the cause of 1 death. All but 1 child (whose parents declined to complete the full series) had received at least 1 age-appropriate dose, but only 2 were old enough to have completed the primary series.

None of the cases in 2003 arose from populations of infants that were newly offered hepatitis B (British Columbia), pneumococcal conjugate (British Columbia, Alberta, Nunavut) or meningococcal group C conjugate (Alberta) vaccinations concurrently with Hib vaccinations.

Two deaths resulted from Hib infection. Neither was classified as preventable, because 1 occurred in a child 1 month old and the other in a child 5 months old.

\section{Interpretation}

IMPACT centres manage about half of the invasive Hib infections affecting Canadian children. ${ }^{9}$ After reporting a historic low of 4 cases in $2000,{ }^{6}$ we were concerned to see the case total reach 16 in 2001, the largest annual total in a decade. The subsequent decrease to 10 cases in 2002 and a new low of 3 cases in 2003 indicates that the fluctuations in case totals were situational and not indicative of declining vaccine effectiveness. During the past 8 years, when all provinces and territories have used the same PRP-T Hib vaccine, the annual case total at IMPACT centres ranged from 3 to 16 , with a mean of 8.4 (95\% confidence interval 5.1-11.7). We should anticipate that future case totals will fall within this range in the absence of changes in vaccine effectiveness or vaccination rates.

A key observation is that the annual number of PRP-T vaccine failures after age-appropriate vaccination has been nearly constant since 1996, ranging from 1 to 4, with only 2 to 3 per year during the period 2001 to 2003 . This is the most direct evidence that the effectiveness of the current vaccination regimen (product and schedule) is stable. Among the 9 vaccine failures in this report, only 2 involved previously healthy children. The others were immunocompromised or had other predisposing conditions. There was no indication of declining protection among infants who received new vaccines concurrently with Hib vaccinations, but it is too early to exclude this possibility, as only a few provinces had implemented new programs with additional vaccines in 2002 and 2003. The number of cases in older children was unchanged from previous years, ${ }^{5}$ which speaks against declining protection with age. The oldest PRP-T vaccines (or vaccine recipients) are now 11-12 years old.

An important contributor to the fluctuation in case totals was variation in the proportion of referred cases. Whereas about half of the cases in 2002 and 2003 were referred from elsewhere, in 2001 referred cases outnumbered local cases by 3 times, accounting for the large total. The reasons for this anomaly are unclear but included an unusual number of referrals from the territories (see later).
Case series data such as these are vulnerable to unrecognized influences on referral practices, particularly because many IMPACT centres serve entire provinces and adjacent territories. On the other hand, one strength of the IMPACT methods is the aggressively complete case ascertainment, which would have revealed changes in local practices such as greater use of outpatient management.

Parental refusal of vaccination accounted for one-quarter of the cases in this series, with severe consequences for some of the children. Parents who refuse vaccination should be informed of the potential consequences for the child. The average annual number of cases associated with parental refusal was unchanged from data obtained in 1998 and $1999 .{ }^{5}$ Accurate data on Hib vaccination rates across Canada are not available, because surveys have been hampered by inaccurate record-keeping for combined vaccines. ${ }^{10}$

Young age was a contributing factor in one-third of the recent cases. With PRP-T vaccine, doses at 2, 4 and 6 months of age are recommended for optimal protection, but most children develop protection after the first or second dose. ${ }^{11}$ Some cases in the first 5 months of life are not preventable with the current regimen, but these are uncommon because of the temporary protection afforded by maternally derived antibody. Where disease risk is increased among young infants, as in Alaskan native communities, ${ }^{12,13}$ a different Hib vaccine (PRP-OMP [PRP conjugated to Neisseria meningitidis outer membrane protein complex]) is potentially advantageous because it rapidly elicits protection after the first or second dose. ${ }^{13,14}$ Use of that vaccine might have prevented more cases in the territories in 2001, as all of those children had received at least 1 dose of Hib vaccine. Census data indicate that 4836 children up to 3 years of age lived in the territories in 2001, so the 5 cases of Hib infection encountered that year reflect an incidence rate of at least 103.4 per 100000 , whereas the reported rate for all of Canada in 2000 was about 1.0 per 100000 for this age group. ${ }^{9}$ An Arctic surveillance project spanning Alaska and the territories is in progress and will provide a more complete assessment of disease rates and optimal control strategies.

The messages from this recent experience are clear: Hib organisms remain dangerous, so children should complete the vaccination series in a timely manner. Among children vaccinated with the current Hib vaccine, breakthrough infections are rare. Surveillance should continue to confirm long-term protection ${ }^{15}$ and to assess the effects of concurrent vaccination with other conjugate vaccines as new provincial programs are implemented.

This article has been peer reviewed.

From the British Columbia's Children's Hospital, Vancouver, BC (Scheifele); IWK Health Centre, Halifax, NS (Halperin); Winnipeg Children's Hospital, Winnipeg, Man. (Law); and Health Canada, Ottawa, Ont. (King)

Competing interests: David Scheifele received an honorarium from the Canadian Paediatric Society to speak on the subject of control of Haemophilus influenzae disease at the society's 2004 annual meeting during a session sponsored by Wyeth Lederle. He also received travel sponsorship from Aventis Pasteur in May 2004 to 
present (without honorarium) the results of a study of Pentacel vaccination at the Society for Pediatric Research annual meeting. Scott Halperin has received an educational grant from Aventis Pasteur, the manufacturer of the vaccine discussed in this paper. No competing interests declared for Barbara Law and Arlene King.

Contributors: David Scheifele, Scott Halperin and Arlene King designed the study. David Scheifele, Scott Halperin and Barbara Law, along with investigators from each of the other IMPACT centres, acquired the data. David Scheifele performed the data analysis and prepared the initial draft of the manuscript. Scott Halperin, Barbara Law and Arlene King contributed to manuscript revisions. All of the IMPACT investigators reviewed and approved the final version submitted.

Acknowledgements: The Immunization Monitoring Program, Active (IMPACT) is funded by Health Canada and managed by the Canadian Paediatric Society. We are grateful for the unstinting efforts of IMPACT monitors, liaison and data centre staff.

\section{References}

1. Haemophilus influenzae infection in Canada, 1969-85. Can Dis Wkly Rep 1986; 12:37-43

2. Scheifele DW, Halperin SA; CPS/Health Canada Immunization Monitoring Program, Active (IMPACT). Immunization Monitoring Program, Active: a model of active surveillance of vaccine safety. Semin Pediatr Infect Dis 2003;14 213-9.

3. Scheifele DW. Recent trends in pediatric Haemophilus influenzae type b infections in Canada. Immunization Monitoring Program, Active (IMPACT) of the Canadian Paediatric Society and the Laboratory Centre for Disease Control. CMA7 1996;154(7):1041-7.

4. Haemophilus influenzae type b disease at 11 pediatric centres, 1996-1997 [published erratum in Can Commun Dis Rep 1998;24(18):151]. Can Commun Dis Rep 1998;24(13):105-8.

5. Haemophilus influenzae type b disease control using Pentacel, Canada, 19981999. Can Commun Dis Rep 2000;26(11):93-6.

6. Historic low Haemophilus influenzae type b case tally - Canada 2000. Can Commun Dis Rep 2001;27(18):149-50.

7. McVernon J, Andrews N, Slack MPE, Ramsay ME. Risk of vaccine failure after Haemophilus influenzae type $\mathrm{b}(\mathrm{Hib})$ combination vaccines with acellular pertussis. Lancet 2003;361:1521-3.

8. Dagan R, Eskola J, Leclerc C, Leroy O. Reduced response to multiple vaccines sharing common protein epitopes that are administered simultaneously to infants. Infect Immun 1998;66:2093-8.

9. Notifiable diseases annual summary - 2000. Can Commun Dis Rep 2003;29 (Suppl 2):20-2.

10. Measuring up: results from the National Immunization Coverage Survey, 2002. Can Commun Dis Rep 2004;30(5):37-50.
11. Hviid A, Melbye M. Impact of routine vaccination with a conjugate Haemophilus influenzae type b vaccine. Vaccine 2004;22:378-82

12. Ward JI, Margolis HS, Lum MKW, Fraser DW, Bender TR, Anderson P. Haemophilus influenzae disease in Alaskan Eskimos: characteristics of a population with an unusual incidence of invasive disease. Lancet 1981;1:1281-5.

13. Galil K, Singleton R, Levine OS, Fitzgerald MA, Bulkow L, Getty M, et al. Reemergence of invasive Haemophilus influenzae type b disease in a wellvaccinated population in remote Alaska. 7 Infect Dis 1999;179(1):101-6.

14. Singleton R, Bulkow LR, Levine OS, Butler JC, Hennessy TW, Parkinson A. Experience with the prevention of invasive Haemophilus influenzae type b disease by vaccination in Alaska: the impact of persistent oropharyngeal carriage. 7 Pediatr 2000;137(3):313-20.

15. Makela PH, Kayhty H, Leino T, Auranen K, Peltola H, Ekstrom N, et al. Long-term persistence of immunity after immunisation with Haemophilus influenzae type b conjugate vaccine. Vaccine 2003;22:287-92.

Correspondence to: Dr. David Scheifele, Rm. L427, British Columbia's Children's Hospital, 4500 Oak St., Vancouver BC V6H 3N1; fax 604 875-2635; dscheifele@cw.bc.ca

Immunization Monitoring Program, Active (IMPACT) investigators and participating centres: Dr. Scott Halperin, IWK Health Centre, Halifax, NS; Dr. Robert Morris, Dr. Charles A. Janeway Child Health Centre, St. John's, Nfld.; Dr. Pierre Déry, Centre hospitalier universitaire de Québec (Pavilion CHUL), Quebec, Que.; Dr. Marc Lebel, Hôpital Sainte-Justine, Montréal, Que.; Dr. Dorothy Moore, Montreal Children's Hospital, McGill University Health Centre, Montréal, Que.; Dr. Nicole Le Saux, Children's Hospital of Eastern Ontario, Ottawa, Ont.;

Dr. Elizabeth Ford-Jones, The Hospital for Sick Children, Toronto, Ont.; Dr. Barbara Law, Winnipeg Children's Hospital, Winnipeg, Man.; Dr. Ben Tan, Royal University Hospital, Saskatoon, Sask.; Dr. Taj Jadavji, Alberta Children's Hospital, Calgary, Alta.; Dr. Wendy Vaudry, Stollery Children's Hospital, Edmonton, Alta.; Dr. David Scheifele, British Columbia's Children's Hospital, Vancouver, BC; Drs. Arlene King and Wikke Walop, Health Canada liaisons, Ottawa, Ont.; Dr. Joanne Embree, Canadian Paediatric Society liaison, Winnipeg, Man.; Dr. John Waters, Alberta Health liaison, Edmonton, Alta. (deceased)

\section{Reprints

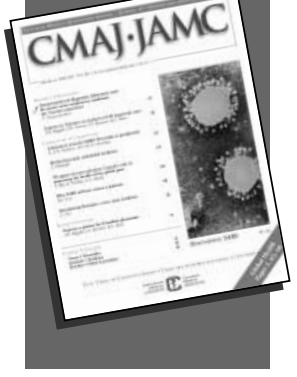 \\ Bulk reprints of $C M A J$ articles are available in minimum quantities of 50 \\ For information or orders: \\ Reprint Coordinator \\ tel $800663-7336 \times 2110$, fax $613565-7704$ \\ janis.murrey@cma.ca

ASSOCIATION
MÉDICALE
CANADIENNE

